\title{
Máscaras de Nós
}

\author{
Sally Santiago
}

Departamento de Comunicação e Artes, Universidade de

Aveiro, Aveiro, Portugal

https://orcid.org/0000-0002-7003-8528

\section{Masks of Ourselves}

Submetido: 25/06/2021 | Revisto: 05/08/2021 | Aceite: 12/08/2021 | Publicado: 06/10/2021

"Sou a verdade que acredito - parte da natureza divina - , sou feita do tempo, das memórias e das marcas do que sei, vi e vivi". Esta foi a frase que se fixou em minha mente depois de muito pensar sobre o que de novo sairia em resposta à pergunta "quem você é?". Esta foi a forma mais concisa de talvez racionalizar os 1.000 caminhos que traçamos para estruturar uma resposta sobre nós mesmos quando convidados - juntar e vestir as nossas próprias verdades.

Questionar quem somos, à primeira vista, revela-se como algo estritamente pessoal, mas é exatamente por meio deste questionamento que a face do que somos perante outros é também reconhecida. A nós é atribuída uma potência de autoconhecimento que tem a sua definição ímpar questionada a partir do momento que a nossa existência está para além de somente nós mesmos.

Este ensaio visual é tecido através do diálogo de frames do vídeo Da Verdade e do Tempo (Santiago, 2020), fruto de uma proposta de criação sob autorreflexão e autorrepresentação, que retrata, por meio da seleção de imagens, uma narrativa que transita de uma esfera íntima para uma esfera de manifestação, de certa forma "auto delimitada". Estabelecemos o diálogo entre uma identidade pessoal e a sua possível mudança quando partilhada - o que eu vejo e o que os outros conseguem ver.

O título "Máscaras de Nós", dado a este ensaio, faz alusão ao diálogo traçado entre máscara e o que esta pode vir a representar, presente no texto "El Origen del Teatro" (A Origem do Teatro) de María Zambrano (2009). Ao afirmar que a máscara é o início do teatro e que esta então dá o caráter de representação à ação dramática, Zambrano (2009) justifica que "a obra dramática é um pedaço da vida irreal que se extrai da vida" (p. 131), atribuindo uma visão de faceta irreal do nós - do que vivemos - que é escolhida por nós para ser mostrada - uma máscara - , premissa aqui adotada e que se completa com a afirmação:

máscara é conhecida no grego, de onde vem a palavra, que significa pessoa ( ... ) é como se a máscara revelasse o que realmente é uma criatura humana, como se trouxesse à tona sua intimidade mais íntima e os acontecimentos mais ocultos de sua vida.

(Zambrano , 2009, p. 132)

Ao reconhecer essa ambiguidade de sentido, trago "Máscaras de Nós", de forma plural, de modo a colocar-me não só a mim como ser que delimita parte de quem sou ou de quem acredito que sou como máscara para o mundo, mas também, levando em conta o caráter assistido que este ensaio incorpora ao ser compartilhado, a convidar o espectador à mesma reflexão.

É sabido que a temática da autorrepresentação é bem conhecida por meio das manifestações artísticas, com um histórico precursor nas autobiografias - ligadas ao universo da literatura, ao texto escrito, ao consolidado histórico do autorretrato - e na pintura, sucedendo-lhe as representações fotográficas - muitas vezes também com caráter biográfico, que então serviram como uma longa ponte de extensão e desenvolvimento para a imagem-movimento. Para além das diferenças entre o explorar a partir da autorrepresentação nesses diferentes media e períodos, 
como "a impossibilidade de sair de si, de se ver o exterior" (Flores, 2005, para. 7) presente na autobiografia escrita, ou a forma completamente diferente como age a fotografia, com "uma forma de fixação" de si (para. 7), me abstive aqui a introduzir diálogos sumários sobre o caminho traçado através deste projeto de videoarte, onde a prática da reflexão sobre si culmina em uma produção final planejada a fim de compartilhamento. Onde a interpretação do eu - antes feita pelo próprio eu - passa a ser uma interpretação do outro - por meio da leitura deste espectador. Algo que faz lembrar o que acontece muitas vezes na fotografia, onde se "instaura uma separação entre a ordem da representação e o olhar do sujeito" (Flores, 2005, para. 8), ou também na fotografia considerada por Roland Barthes (1980/2017) como "o aparecimento de eu próprio como outro, uma dissociação artificiosa da consciência da identidade" (p. 28), reconhecendo diferentes imaginários em uma mesma representação, existindo simultaneamente um eu que é "aquele que eu julgo ser [e], aquele que eu gostaria que os outros julgassem que eu fosse" (p. 30). Estas constituem características representativas do caráter multifacetado da manifestação artística, vinda da autorreflexão e autorrepresentação, a partir da sua estreia como uma manifestação compartilhada.

A autonomia que essa representação ganha, a partir da sua partilha, de nenhum modo apaga todo o "eu" escolhido para ser imputado na autorrepresentação, mas abre espaço para que este mesmo "eu" possa ultrapassar o que ali - na tal representação - escolheu ser. Esse caráter de um despertar de autonomia após o "nascimento" da representação é muitas vezes observado nas fotografias de Jo Spencer e Nan Goldin. Além de não apresentarem uma abordagem formal na fotografia, ambas usam a fotografia "como uma busca permanente de uma identidade fixa que sabem ser utópica; uma busca de uma imagem de redenção cuja procura apenas as pode afastar ainda mais" (Flores, 2005, para. 52), de forma a reconhecer não apenas a escolha de uma narrativa delimitada para a autorrepresentação - até mesmo utópica - , como também a possibilidade de criar-se um novo "espaço" para ultrapassar aquilo que por elas foi delimitado. Seja por meio das fotografias de Jo Spencer, ao representar o seu próprio corpo doente, fotografias que após serem expostas se tornaram pedaços de uma certa luta sobre a política do corpo e a sua relação com os padrões de beleza. Seja por meio de um dos raros autorretratos - formais - de Nan Goldin, Nan, Depois de Ter Sido Espancada ${ }^{1}$ (1984), que após exibidos transformou-se em um dito gesto político. A questão aqui se assemelha à narrativa apresentada, pois, apesar do abandono do formalismo fotográfico comumente encontrado nas autorrepresentações que antecederam o contemporâneo, e apesar da busca por uma identidade fixa, ambas as fotógrafas "nunca deixaram de ser ( ... ) verdadeiras máscaras" (Flores, 2005, para. 59) em suas autorrepresentações.

Essa nova leitura possível de ser descolada da narrativa inicial, delimitada pelo artista ao se autorrepresentar, pode ter como uma possível explicação o que Walter Benjamin (1936/1992) chama de "inconsciente óptico", ao descrever um inconsciente que deixa escapar os limites delimitados por quem está a criar, neste caso, o autor da autorrepresentação. Este aspecto pode ser melhor compreendido em uma colocação feita ao relacionar-se com o cinema:

em vez de um espaço preenchido conscientemente pelo homem, surge um outro preenchido inconscientemente. Mesmo que seja comum observar, ainda que grosseiramente, o andar das pessoas, nada se sabe da sua atitude na fracção de segundo em que avançam um passo. Em geral, o acto de pegar num isqueiro ou numa colher é-nos familiar, mas mal sabemos o que se passa entre a mão e o metal ao efectuar esses gestos, para não falar de como neles actua a nossa flutuação de humor. Aqui a câmara intervém com os seus meios auxiliares, os seus "mergulhos" e subidas, as suas interrupções e isolamentos, os seus alongamentos e acelerações, as suas ampliações e reduções. A câmara leva-nos ao inconsciente óptico, tal como a psicanálise ao inconsciente das pulsões.

(Benjamin, 1936 /1992, p. 104)

Ao tratar de imagem em movimento, esta colocação, referindo-se ao cinema, dialoga com o "espaço" oculto referido anteriormente, onde o artista deixa passar outros sentidos para a sua representação, muitas vezes de forma inconsciente, mas que certamente contribuem para a leitura 
estendida do espectador, que vem ocupar o espaço para além do delimitado. Este espaço, de certa forma, faz parte da composição da tal máscara criada pelo autor, uma nova faceta, desta vez construída pelo delimitado acrescido da nova leitura, cumprindo assim com o papel de autorrepresentação ao mesmo tempo que reconhece a máscara sendo criada e exposta através dela.

Em 1968, Bruce Nauman apresenta um de seus trabalhos em filme (posteriormente transferido a vídeo), intitulado Art Make-Up (MoMA, s.d.), dividido em uma série de quatro partes, contendo 10 minutos cada, onde Nauman aparece em frente a um fundo claro sem camisa, sendo enquadrado do dorso para cima. Afundando os seus dedos em um pequeno recipiente de maquiagem, começa a espalhá-la por todo o seu rosto e corpo até que este estivesse preenchido por completo pelo pigmento, que varia de cor em cada uma das partes do vídeo, passando entre o branco, rosa, vermelho e ao final, preto, sempre uma sobre a outra. Este trabalho pode ser lido de forma paralela à narrativa aqui já apresentada, onde a criação de camadas em seu próprio corpo traz a possibilidade de o autor ser visto em diferentes cores - de diferentes formas, que em certo momento nos faz observar a dinâmica entre a aparência de uma pessoa e as suposições que os outros poderão fazer sobre a sua própria identidade. O autor deixa, mesmo de forma bastante explícita, a real possibilidade de nos mascararmos ao nos autorrepresentarmos, assim como a ideia de novas visões externas surgirem a partir do compartilhar desta representação.

A videoinstalação de Gabriela Golder, Dolor (Dor, 2010), remete também para esta ideia. A autora apresenta simultaneamente seis vídeos de mulheres lendo um determinado texto em busca de se expressarem, gerando um grande murmúrio de sobreposição de vozes que deixa "evidente a complexidade do autorretrato videográfico em que o self também aparece no olhar dos outros", ou "como diria María Luisa Ortega, na experiência de estar ali, 'como a marca de um cineasta com a intenção de voar na parede'”, o que permite o aparecimento de outras formas do eu (Varela, 2010, p. 82). Esta videoinstalação leva-nos a reconhecer o possível espaço de leitura para além do auto delimitado pelo artista responsável por sua representação.

A videoarte Da Verdade e do Tempo (2020), origem dos frames aqui apresentados, surgiu a partir da pergunta "quem sou?", que sucedeu à resposta escrita na primeira frase deste ensaio. Neste contexto, tenho a verdade - a minha - e o tempo, e tudo o que acredito que estes contemplem, de certa forma como anunciadores da resposta à pergunta proposta, como uma máscara de mim. Esta autorrepresentação videográfica já nasceu com a consciência de uma narrativa de quem sou delimitada, assim como com a ânsia do compartilhar, a fim de abrir o espaço para o reflexo do eu no olhar do outro, assim como para a leitura externa de formas deste mesmo eu.

Não devo deixar de dizer também que o contexto de isolamento causado pelo período pandêmico foi um fator essencial e intensificador na criação do vídeo, tendo a sua composição sido feita apenas por cenas indoor ou de arquivo pessoal, o que, consequentemente, estabeleceu uma forte influência na reflexão da proposta autorreferencial. Acredito que, apesar do momento e ambiente condicionados, a experiência da criação se enriqueceu, pelo seu caráter de intimidade, visto que o espaço - lar, diário, rotineiro - atuou completamente de forma cooperativa na convivência com o mais íntimo, que aqui se fez essencial para a composição. Como se o viver com você mesmo nunca tivesse sido vivido sob olhos tão atentos, tão presentes.

Não nego o desconforto presente na autorreflexão, quem dirá na autorrepresentação, e acredito que o vídeo em seu produto final tenha sido fruto de uma desistência de revelar uma completude e mais uma escolha de narrativa parcial, mas, ainda assim, intimamente verdadeira. Assim, pelos primórdios da pintura, onde nos emprestaram o seu desenvolvimento precursor em autorretrato, para dar continuidade ao caminho que hoje culmina na autorrepresentação em imagem movimento, ouso apropriar-me então da expressão do pintor René Magritte, ao descrever a sua dificuldade em pintar o seu próprio retrato - o tão conhecido O Filho do Homem (1964) - como "problema de consciência", e garantir entregar neste vídeo uma autorrepresentação minha ao mesmo tempo que entrego somente o que quero - o que deixo - sobre mim, assim como a face tapada pela maçã no 


\section{Vista}

N.o 8 (2021): Julho - dezembro 2021 | https://doi.org/10.21814/vista.3502

quadro de Magritte.

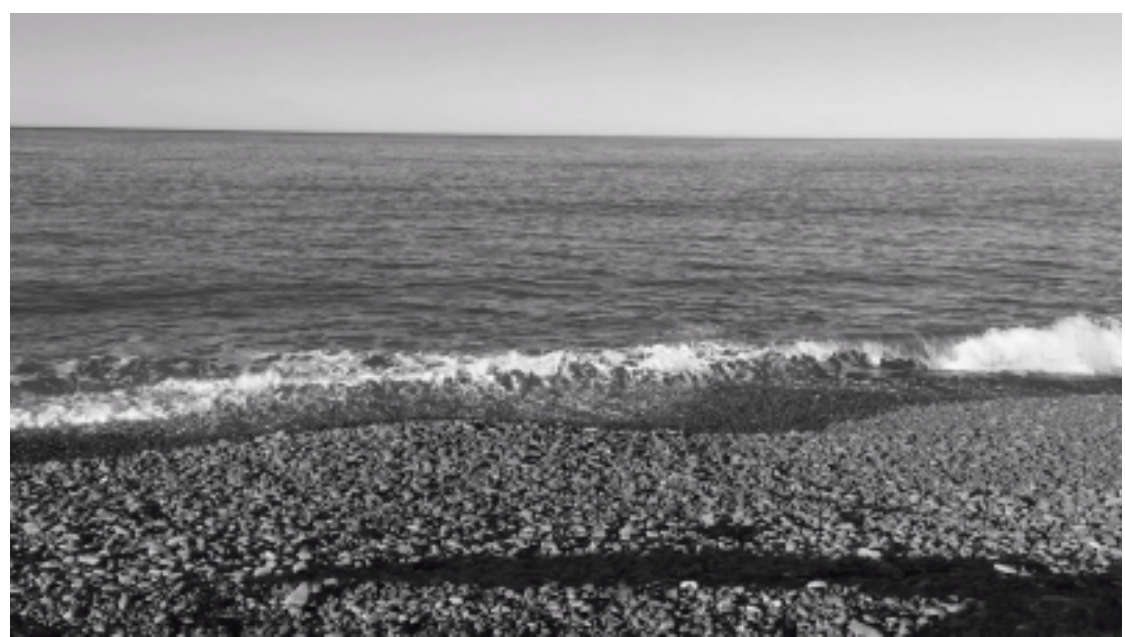

Figura 1. O fim da tarde ao dormir em pedras, Kaikoura - Nova Zelândia Fonte. De Da Verdade e do Tempo (00:00:06), de S. Santiago, 2020. Copyright 2020 de Sally Santiago.

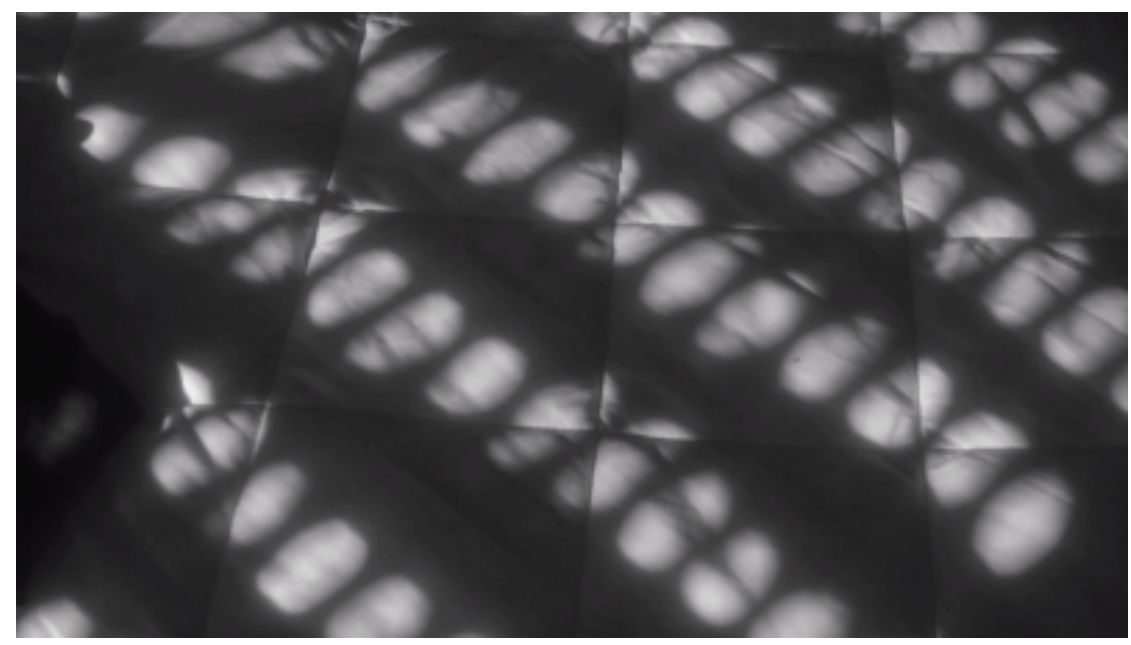

Figura 2. Na manhã ao acordar sem abrir a janela Fonte. De Da Verdade e do Tempo (00:00:27), de S. Santiago, 2020. Copyright 2020 de Sally Santiago.

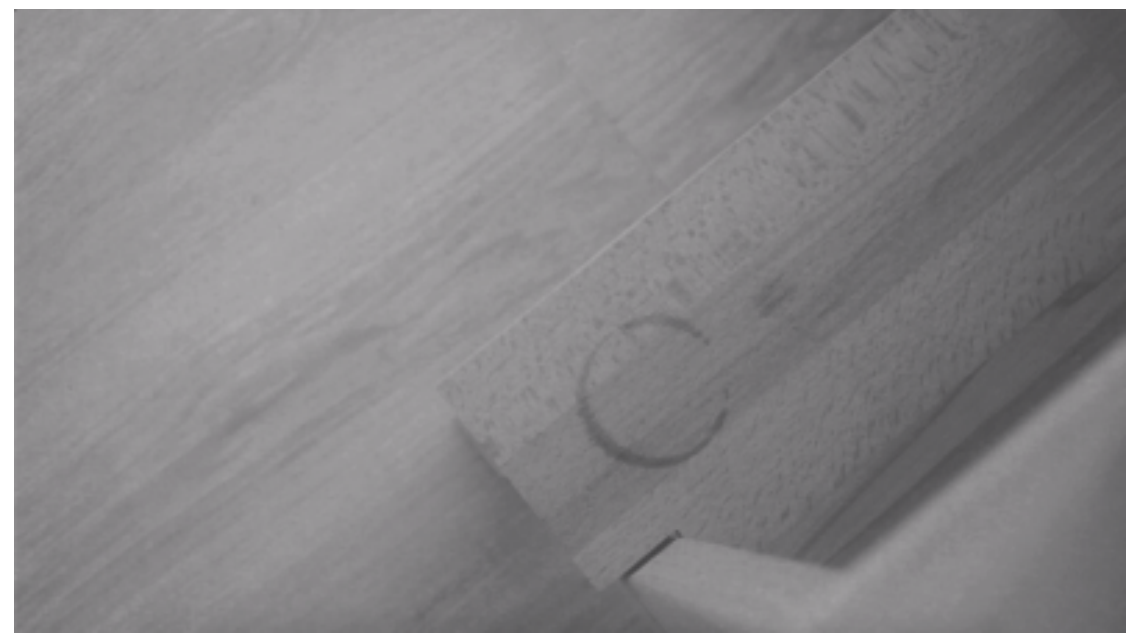

Figura 3. Mais uma andança, mais um copo Fonte. De Da Verdade e do Tempo (00:00:44), de S. Santiago, 2020. Copyright 2020 de Sally Santiago. 


\section{Vista}

461. N.o 8 (2021): Julho - dezembro 2021 | https://doi.org/10.21814/vista.3502

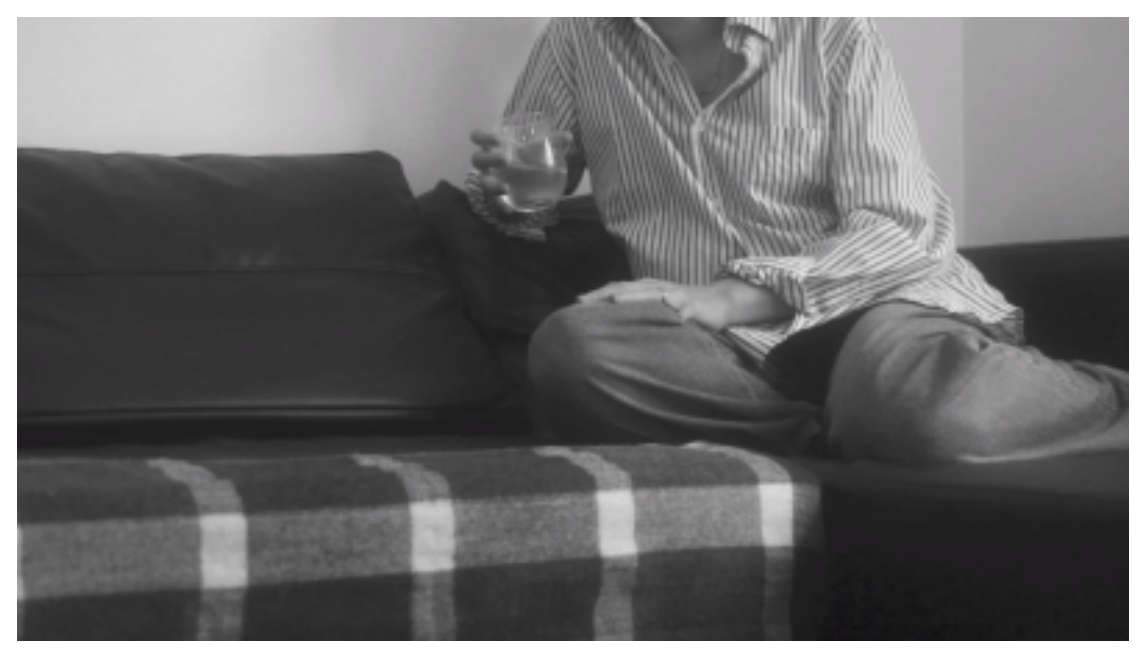

Figura 4. Uma música toca mas o murmúrio da multidão não cala Fonte. De Da Verdade e do Tempo (00:01:05), de S. Santiago, 2020. Copyright 2020 de Sally Santiago.

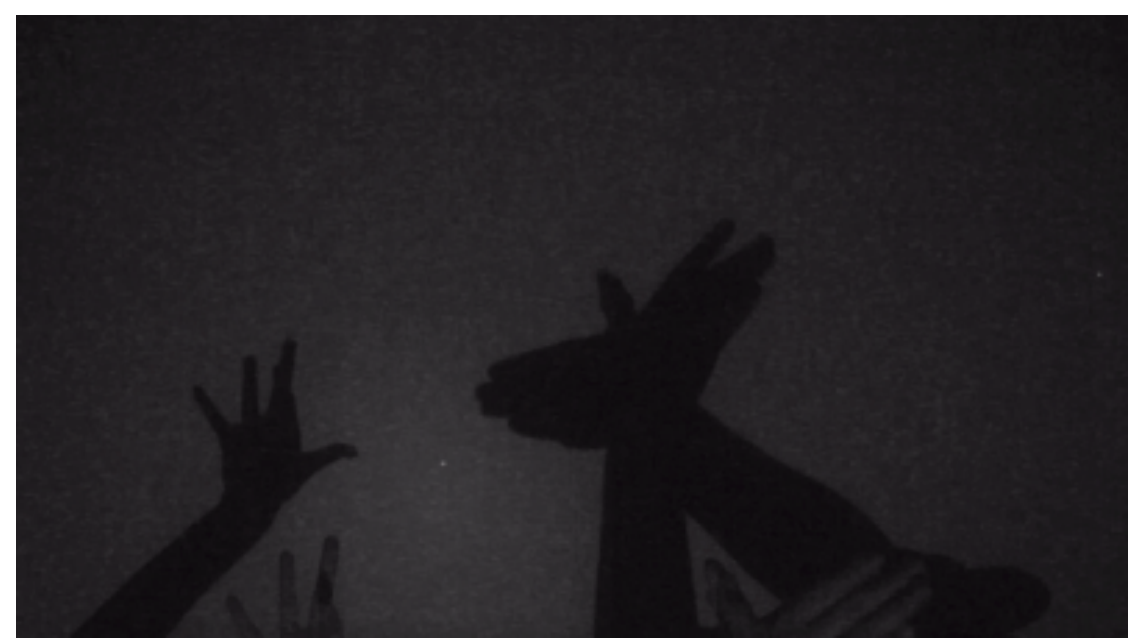

Figura 5. Não sei se foi ontem ou se ainda é hoje Fonte. De Da Verdade e do Tempo (00:02:01), de S. Santiago, 2020. Copyright 2020 de Sally Santiago.

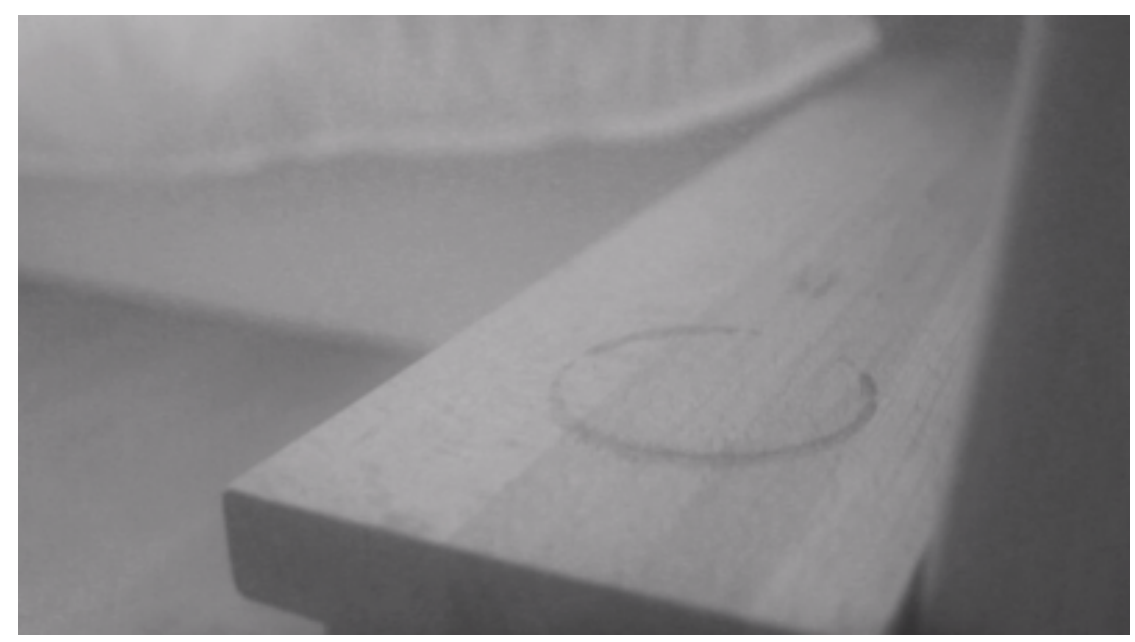

Figura 6. Mais uma andança, mais um copo, mais uma marca Fonte. De Da Verdade e do Tempo (00:01:37), de S. Santiago, 2020. Copyright 2020 de Sally Santiago. 


\section{Vista}

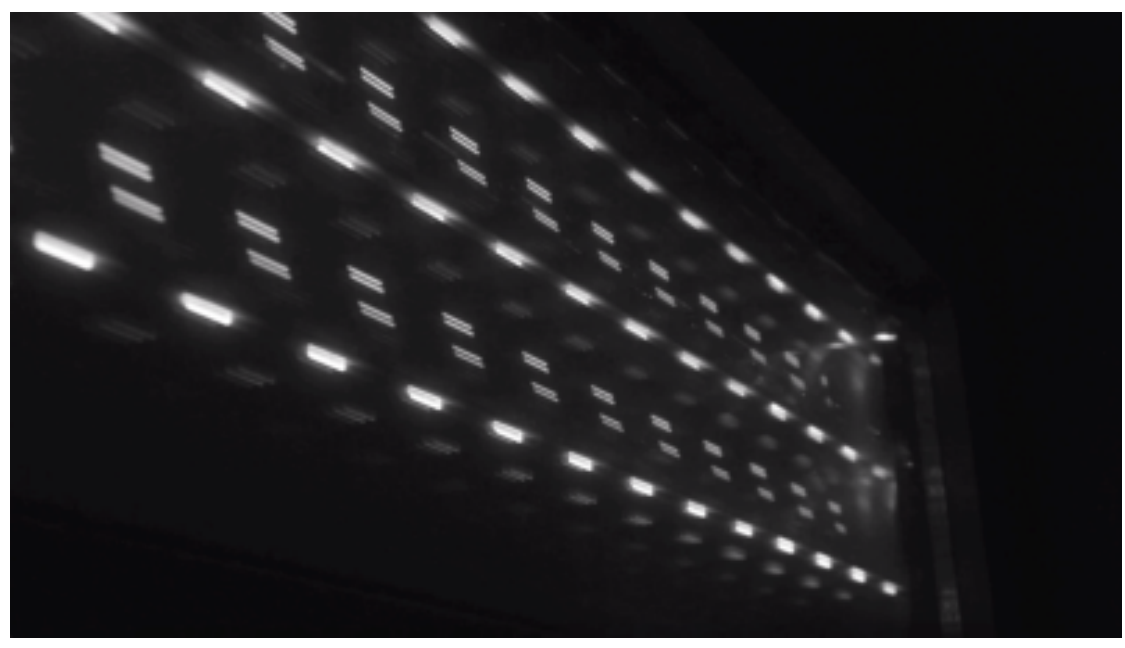

Figura 7. Na manhã ao olhar uma janela Fonte. De Da Verdade e do Tempo (00:00:22), de S. Santiago, 2020. Copyright 2020 de Sally Santiago.

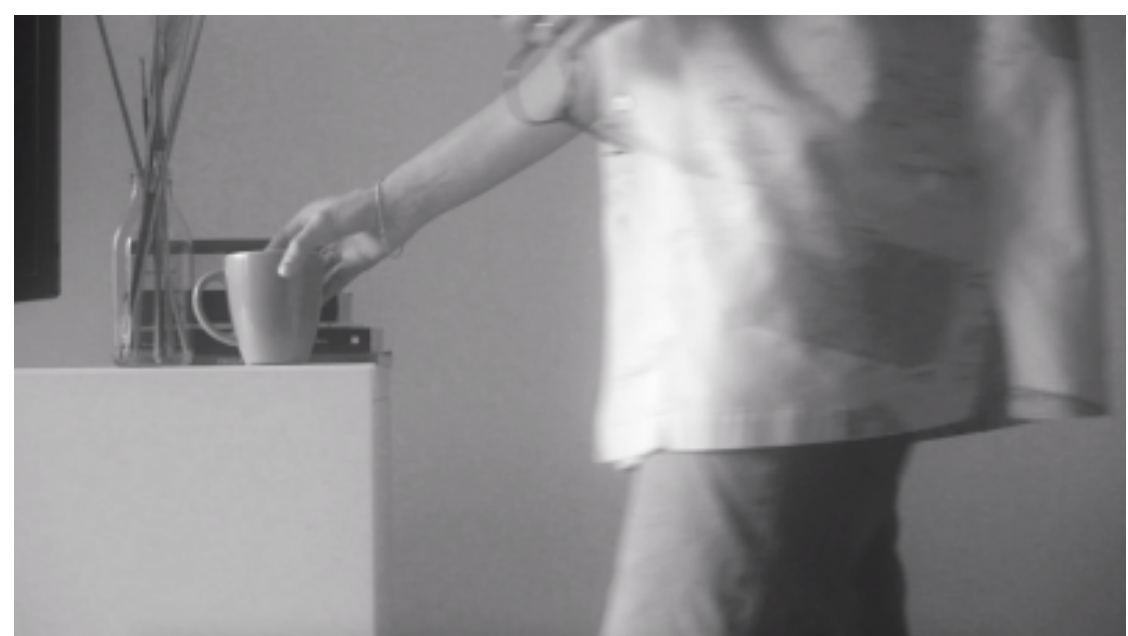

Figura 8. Mais uma andança, mais uma troca Fonte. De Da Verdade e do Tempo (00:01:31), de S. Santiago, 2020. Copyright 2020 de Sally Santiago.

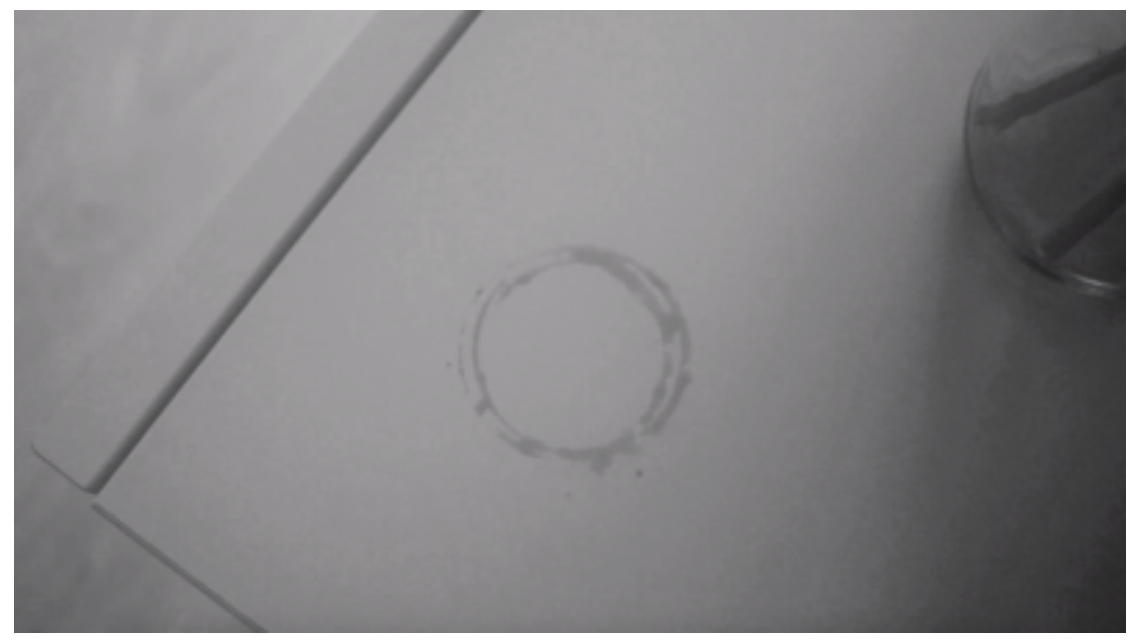

Figure 9. Mais uma andança, mais um copo, mais uma marca, passa o tempo De Da Verdade e do Tempo (00:00:46), de S. Santiago, 2020. Copyright 2020 de Sally Santiago. 


\section{Vista}

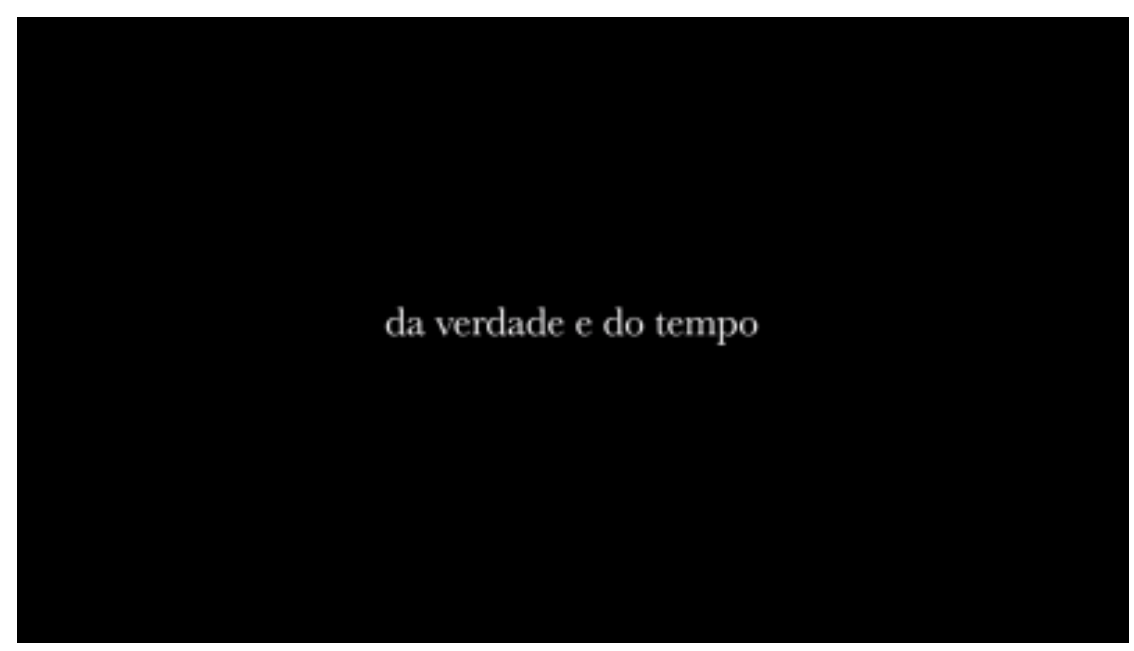

Figure 10. A resposta Fonte. De Da Verdade e do Tempo (00:03:32), de S. Santiago, 2020. Copyright 2020 de Sally Santiago.

\section{Nota Biográfica}

Sally Santiago é artista visual e mestranda em criação artística contemporânea na Universidade de Aveiro (Departamento de Comunicação e Artes). Possui graduação em comunicação social (2017) pela Universidade Anhembi Morumbi (São Paulo). Seus projetos habitam sobretudo o campo do vídeoarte, assim como desdobramentos experimentais; seus focos de pesquisa permeiam debates entre as experiências humanas, seus processos de mudança, a percepção de si e a conexão com os espaços, o habitar na grandeza.

ORCID: https://orcid.org/0000-0002-7003-8528

Email: sallysantiago_@hotmail.com

Morada : Departamento de Comunicação e Arte, Campus Universitário de Santiago, Universidade de Aveiro, Aveiro, Portugal

\section{Notas}

1. Pertencente à coleção do Tate, desde 1977.

\section{Referências}

Barthes, R. (2017). A câmara clara (M. Torres, Trad.). Edições 70. (Trabalho original publicado em 1980)

Benjamin, W. (1992). Sobre arte, técnica, linguagem e política (M. Alberto, M. A. Cruz \& M. L. Moita, Trad.). Relógio d’Água. (Trabalho original publicado em 1936)

Flores, T. M. (2005). Fotografia, auto-retrato e autobiografia. Comunicação Pública, 1(2), 121-144. https://doi.org/10.4000/cp.9123

MoMA. (s.d.). Nauman, B. Art make-up: No. 1 white, No. 2 pink, No. 3 green, No. 4 black. MoMA Learning. https://www.moma.org/learn/moma learning/bruce-nauman-art-make-up-no-1-whiteno-2-pink-no-3-green-no-4-black-1967-1968/ 
Santiago, S. (2020). Da verdade e do tempo [videoarte]. Acervo particular.

Varela, F. (2010). El autorretrato videográfico: The video art self-portrait. Revista de Humanidades, $21,69-85$.

Zambrano, M. (2009). Las palabras del regreso. Catedra.

Este trabalho está licenciado com uma Licença Creative Commons - Atribuição 4.0 Internacional . 